HELMINTHOLOGIA, 57, 2: 154 - 157, 2020

Case Report

\title{
The fatal case of an autochthonous heartworm disease in a dog from a non-endemic region of south-eastern Slovakia
}

\author{
M. MITERPÁKOVÁ1, H. ZBOROVSKÁ2 ${ }^{2}$ B. BIELIK², M. HALÁN ${ }^{3, *}$ \\ ${ }^{1}$ Institute of Parasitology, Slovak Academy of Sciences, Hlinkova 3, 04001 Košice, Slovakia; ${ }^{2}$ University Veterinary Hospital, \\ University of Veterinary Medicine and Pharmacy in Košice, Komenského 73, 04001 Košice, Slovakia; ${ }^{*}$ Department of Epizootology \\ and Parasitology, University of Veterinary Medicine and Pharmacy in Košice, Komenského 73, 04001 Košice, Slovakia, \\ E-mail: halan@uvlf.sk
}

Article info

Received February 7, 2020

Accepted March 16, 2020

\section{Summary}

During the past few years, several localities with increasing Dirofilaria immitis occurrences have been identified in Slovakia; particularly in areas regarded as endemic for Dirofilaria repens up until now. In terms of that, dogs with clinically manifested heartworm disease have been referred to the veterinary ambulances more frequently. We report in this study, two autochthonous cases of $D$. immitis-infections diagnosed in two seven-year-old siblings of Tibetan Mastiff dogs from the Košice region of south-eastern Slovakia. The course of the disease in both dogs were very different. The female dog did not manifest any unusual findings, however the male dog exhibited severe clinical signs of heartworm disease that lead to his death. The subsequent autopsy revealed adult $D$. immitis worms in the right heart ventricle and pulmonary arteries.

Keywords: Dirofilaria immitis; heartworm disease; fatal outcome; dog; Slovakia

\section{Introduction}

The causative agent of canine heartworm disease is the mosquito-borne Dirofilaria immitis (Spirurida: Onchocercidae). The disease within Europe is wide-spread mainly in the temperate Mediterranean regions of Italy, Spain, Portugal and Greece (Simón et al., 2012). In other parts of Europe a related species (Dirofilaria repens) is responsible for the less serious subcutaneous and ocular dirofilariosis which occurs more frequently (Capelli et al., 2018). In Slovakia, the first cases of canine dirofilariosis were diagnosed fifteen years ago (in 2005) in the south-western part of the country. During the first epidemiological monitoring, encompassing an investigations of more than 4,000 dogs, $D$. repens was detected with a mean prevalence ranging between $2 \%$ and $25 \%$ depending upon the region. On the other hand, $D$. immitis was confirmed very rarely; between 2005 and 2015 only ten dogs were reported to have been infected (Miterpáková et al., 2016). This situation has been altered during the last five years and $D$. immitis has increased its prevalence. Only recently, have heartworm cases been detected in a breeding establishment in south-western Slovakia (Miterpáková et al., 2018) and new autochthonous infections have been recorded regularly during routine diagnostic procedures at the Institute of Parasitology SAS (IP SAS).

The clinical presentation of heartworm disease is very heterogeneous; from no symptoms (for several months, even years) up to a serious "caval syndrome" leading to the displacement of worms from the pulmonary arteries into the right cardiac chambers. Liver congestion and jugular pulsation may be observed as a result of the tricuspid valve obstruction by the parasites. This condition is often associated with anaemia, haemoglobinaemia and haemoglobinuria. Changes in haematological and biochemical profile often become evident only during the last stages of the infection (ESDA, 2017).

\footnotetext{
* - corresponding author
} 
Here, we report for the first time a fatal case of heartworm disease in a dog from a previously non-endemic area in south-eastern Slovakia.

\section{Cases presentation}

The patients described here were two seven-year-old canine Tibetan Mastiff siblings; an intact male (Dog 1) and a female (Dog 2) who were kept together by the same owner. The dogs had never been treated with heartworm preventatives, no anti-ectoparasites prophylaxis had been used, and even routine vaccinations had been omitted in the last few years.

\section{$\operatorname{Dog} 1$}

In December 2019, a 7-year-old 50 kg male Tibetan Mastiff dog was referred to the veterinary hospital at the University of Veterinary Medicine and Pharmacy (UVMP) in Košice because of acute weakness and apathy. He suffered from anorexia and vomiting. The clinical examination revealed: an elevated body temperature $\left(39.8^{\circ} \mathrm{C}\right)$, anaemic mucous membranes and pain in the abdomen. Epistaxis from both nostrils was also observed. The breathing frequency and pulse were normal. The lymph nodes were not enlarged, auscultation of the heart was normal, without any murmurs, and the respiratory sounds were normal. No jugular vein pulsations were observed. During the hospitalization, the patient was found to be oliguric.

A blood examination and ultrasonography (USG) of the abdomen were performed. The haematological examination revealed a leucocytosis and neutrophilia; biochemistry showed an elevated alkaline phosphatase. Other parameters were within the normal reference ranges. However, the creatinine and urea levels started to rise sharply during following days. The USG exam revealed an increased liver hyperechogenicity, mild hepatomegaly with highlighted portal veins and the presence of the sediment in the gallbladder. The stomach contractions and intestine peristalsis were slowed down, with fluid stagnation in the stomach. The caecum was filled with fluid as well as some segments of the small intestine. The urinary bladder was distended with significant sediment inside. The prostate and both of the kidneys were of normal size and echogenicity.

Canine pancreatic lipase test $\left(\mathrm{SNAP} \circledast \mathrm{CPL}^{\mathrm{TM}}\right.$ Test IDEXX Laboratories, Inc., Westbrook, ME, USA) was performed with positive results. The SNAP® Lepto test (IDEXX Laboratories, Inc., Westbrook, ME, USA) for the detection of Leptospira-antibodies was negative.

The specific gravity of the urine was measured with a value of $1018 \mathrm{~kg} / \mathrm{m}^{3}$; the $\mathrm{pH}$ of the urine was 6.0 . Leukocytes, erythrocytes, squamous and tubular cells were detected in the urinary sediment. The dog was also tested using a rapid test system registered for the detection of $D$. immitis antigen and specific antibodies to synthetic peptides of Anaplasma phagocytophilum/Anaplasma platys, Borrelia burgdorferi s.l., Ehrlichia canis and Ehrlichia ewingii

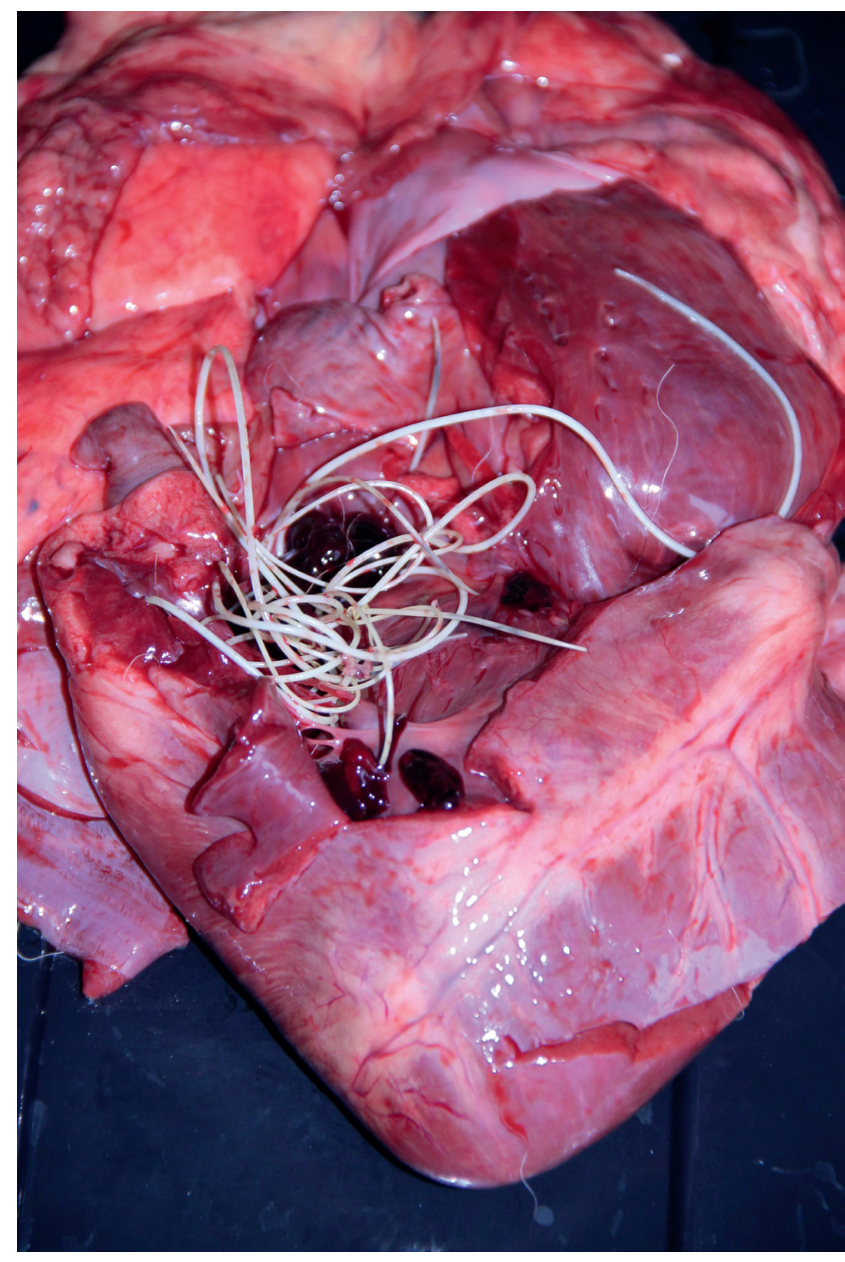

Fig. 1. Adult Dirofilaria immitis worms in the right heart ventricle of Tibetan Mastiff male dog.

(SNAP® 4Dx® Plus, IDEXX Laboratories, Inc., Westbrook, ME, USA) with positive results for $D$. immitis. Subsequently, the diagnosis was confirmed at IP SAS, Košice, using the PCR approach. Briefly, DNA was extracted from the blood using DNeasy Blood and Tissue Kit (Qiagen, Germany) and subsequently fragments of cytochrome $c$ oxidase were amplified with $D$. immitis and $D$. repens specific primers using conventional PCR (Rishniw et al., 2006).

The cardiologic examination was planned, however, the condition deteriorated and dyspnoea appeared. The $\mathrm{X}$-ray revealed an alveolar pattern in the cranial lung lobes and the heart silhouette was not visible due to changes in the lungs. The dog died after 5 days and no other examinations could be performed. The dog was submitted for post-mortem examination and adult $D$. immitis worms were found in the right heart ventricle, and several specimens were identified in the pulmonary arteries (Fig. 1). In addition, pulmonary oedema was discovered and the right ventricle was dilated. The necropsy findings included: chronic interstitial nephri- 
tis and chronic cystitis, acute catarrhal jejunitis, sediment in the gallbladder and icterus. Cardiovascular and respiratory failure in connection with kidney damage was assigned as an immediate cause of the death.

\section{$\operatorname{Dog} 2$}

Another dog from the same owner was referred to our clinic several days later. This 7-year-old female Tibetan Mastiff, was born in the same litter as dog 1 and they were kept together in the same household. This dog did not manifest any signs of the heartworm disease, but numerous microfilariae were detected in a blood smear. Additionally, a SNAP® 4Dx® Plus Test was performed for the detection of circulating $D$. immitis female antigen and was positive. The DNA analysis unambiguously confirmed the heartworm infection. The results of further haematological and biochemical examinations yielded values within the normal reference ranges. The value of renal biomarker SDMA (symmetric dimethylarginine) was $8 \mu \mathrm{g} / \mathrm{dL}$ (reference interval for adult dogs: $0-14 \mu \mathrm{g} / \mathrm{dL}$ ) and the echocardiography revealed no abnormalities.

An alternative therapeutic protocol with macrocyclic lactones and doxycycline was proposed in the female patient due to the unavailability of the melarsomin dihydrochloride (Savadelis et al., 2017; ESDA, 2017) regimen. Eventually, the treatment selected involved monthly applications of imidacloprid/moxidectin (10\%/2.5\%) for 9 months and doxycycline administration at a dose of $10 \mathrm{mg} / \mathrm{kg}$ twice daily for the first 30 days. Additionally, prednisone was administered at a dose of $0.5 \mathrm{mg} / \mathrm{kg}$ twice daily for the first week, then it was reduced to $0.5 \mathrm{mg} / \mathrm{kg}$ once daily for another week and subsequently the dose of $0.5 \mathrm{mg} / \mathrm{kg}$ every 48 hours was given during the third and fourth weeks.

Currently (in February 2020), the treatment is still in progress and the patient is monitored at the University Hospital of UVMP in Košice.

\section{Discussion and Conclusions}

Both dogs came from the village of Nižná Myšla situated $15 \mathrm{~km}$ from Košice which is the largest city of eastern Slovakia $\left(48^{\circ} 37^{\prime} 25^{\prime \prime N}\right.$; $21^{\circ} 21^{\prime} 55^{\prime \prime E}$ ). In this region, canine dirofilariosis, caused by $D$. repens, was first diagnosed in 2007. Since then, a total of 948 blood samples of dogs living in the districts of Košice and Košice-Okolie (eng. Košice-Surrounding) have been examined for microfilariae at IP SAS until the end of 2019. Of them, 89 were tested positive for $D$. repens $(9.4 \%)$. On the contrary, D. immitis was confirmed only in five dogs; in 2011 (a dog from Čaňa village in Košice-Okolie district), in 2017 (a dog from Košice city) and finally, in 2019 in three dogs from Nižná Myšla, Košice-Okolie, including the two cases presented in this report. It was confirmed that the autochthonous heartworm infections occurred in that village as no travelling history was mentioned in the anamnesis. Anyway, in recent years, localities with increased occurrences of $D$. immitis were identified in Slovakia. Interestingly, these areas have been regarded as endemic for $D$. repens until now (Miterpáková et al., 2018). In this regard, the competent authorities, including veterinary practitioners in affected regions should take note. The significance of preventive measures should not be underestimated and dogs should be periodically monitored for microfilariae and for circulating antigens, especially in localities where dirofilariae were previously detected, because microfilaremic dogs serve as an important reservoir of the parasite for both humans and other animals (Stoyanova et al., 2019; Velev et al., 2019). Also, taking into account the recent global trends in traveling and trading, the risk of accidental imported heartworm infections is constantly increasing (Sabūnas et al., 2019).

\section{Ethical Approval and Informed Consent}

No animals were killed for any purpose in this study.

\section{Conflict of interest}

The authors declare that they have no conflict of interest.

\section{Acknowledgements}

This work was supported by the Cultural and Educational Grant Agency of the Ministry of Education, Science, Research and Sport of the Slovak Republic - project KEGA 009UVLF-4/2018 (0.9) and by the Slovak Research and Development Agency under the contract No. APVV-15-0114 (0.1).

\section{References}

Capelli, G., Genchi, C., Baneth, G., Bourdeau, P., Brianti, E., CardoSo, L., Danesi, P., Fuehrer, H.-P., Giannelli, A., lonică, A. M., Maia, C., Modrý, D., Montarsi, F., Krücken, J., Papadopoulos, E., Petrić, D., Pfeffer, M., Savić, S., Otranto, D., Poppert, S., Silaghi, C. (2018): Recent advances on Dirofilaria repens in dogs and humans in Europe. Parasit Vectors, 11: 663. DOI: 10.1186/s13071-018-3205-x

ESDA. EuROPEAN SOCIETY of DiROFILARIOSIS ANd AngIOSTRONGyLOSIS (2017): Guidelines for Clinical Management of Canine Heartworm Disease. Retrieved from https://www.esda.vet/wp-content/ uploads/2017/11/GUIDELINES-FOR-CLINICAL-MANAGEMENT-OF-CANINE-HEARTWORM-DISEASE.pdf

Miterpáková, M., Iglódyová, A., Čabanová, V., Stloukal, E., MıKLIsovÁ, D. (2016): Canine dirofilariosis endemic in Central Europe-10 years of epidemiological study in Slovakia. Parasitol Res., 115(6): 2389 - 2395. DOI: 10.1007/s00436-016-4989-2

Miterpáková, M., ValentovÁ, D., Čabanová, V., Berešíková, L'. (2018): Heartworm on the rise - new insights into Dirofilaria immitis epidemiology. Parasitol Res., 117(7): 2347 - 2350. DOI: $10.1007 /$ s00436-018-5912-9

Rishniw, M., Barr, S.C., Simpson, K.W., Frongillo, M., Franz, M., Dominquez AlpizAR, J.L. (2006): Discrimination between six species 
of canine microfilariae by a single polymerase chain reaction. Vet Parasitol, 135: 303 - 314. DOI: 10.1016/j.vetpar.2005.10.013

Sabūnas, V., Radzijevskaja, J., Sakalauskas, P., Paulauskas, A. (2019): First report of heartworm (Dirofilaria Immitis) infection in an imported dog in Lithuania. Helminthologia, 56(1): 57 -61. DOI: 10.2478/helm-2018-0036

Savadelis, M.D., Ohmes, C.M., Hostetler, J.A., Settje, T.l., Zolynas, R., DzImIANSKI, M.T., Moorhead, A. (2017): Assessment of parasitological findings in heartworm-infected beagles treated with Advantage Multiß for dogs (10\% imidacloprid $+2.5 \%$ moxidectin) and doxycycline. Parasite Vectors, 10: 245. DOI: 10.1186/s13071017-2190-9
Simón, F., Siles-Lucas, M., Morchón, R., González-Miguel, J., Mellado, I., Carretón, E., Montoya-Alonso, J.A. (2012): Human and animal dirofilariasis: the emergence of a zoonotic mosaic. Clin Microbiol Rev, 25: 507 - 544. DOI: 10.1128/CMR.00012-12

Stoyanova, H., Carretón, E., Montoya-Alonso, J.A. (2019): Stray dogs of Sofia (Bulgaria) could be an important reservoir of heartworm (Dirofilaria immitis). Helminthologia, 56(4): 329 - 333. DOI: 10.2478/helm-2019-0033

Velev, V., Vutova, K., Pelov, T., Tsachev, I. (2019): Human dirofilariasis in Bulgaria between 2009 and 2018. Helminthologia, 56(43): 247 - 251. DOI: 10.2478/helm-2019-0016 